\title{
Promoting Education for Sustainable Development with an Interactive Digital Learning Companion Students Use to Perform Collaborative Phosphorus Recovery Experiments and Reporting
}

Johann Seibert, ${ }^{* 1,3}$ Isabel Schmoll, ${ }^{2}$ Christopher W. M. Kay, ${ }^{1,4}$ and Johannes Huwer ${ }^{*}$

${ }^{1}$ Physical Chemistry and Didactics of Chemistry, University of Saarland, Saarbrücken, 66123,

Germany

${ }^{2}$ Chemistry and Chemistry Education, Weingarten University of Education, Weingarten, 88250, Germany

3Science Education, University of Konstanz, Konstanz, 78457, Germany

${ }^{4}$ London Centre for Nanotechnology, University College London, London WC1H OAH, United Kingdom

\begin{abstract}
Multitouch learning books (MLB) are learning companions that support learning within a series, independent of the learning location. These MLBs can accompany an experiment itself or an entire learning process. In addition to providing interactive tasks, an all-in-one solution can provide pupils with additional information, supporting and differentiating aids, in-depth exercises, and collaborative tasks in one location. This article presents an interactive learning companion that facilitates student learning through digital interaction while also developing concepts of sustainability in students' minds. For this purpose, a learning scenario was developed that simulates a virtual learning company in an interactive e-book that corresponds to real experiments carried out in a laboratory. Using this interactive e-book, pupils receive e-mail messages from their "supervisors", give account to the "board of directors", and finally evaluate four real processes for phosphorus recovery. The entire series was qualitatively tested with 89 tenth-grade students. Assessment of these students found a significant increase in their use and understanding of digital tools and awareness of education for sustainable development concepts.
\end{abstract}




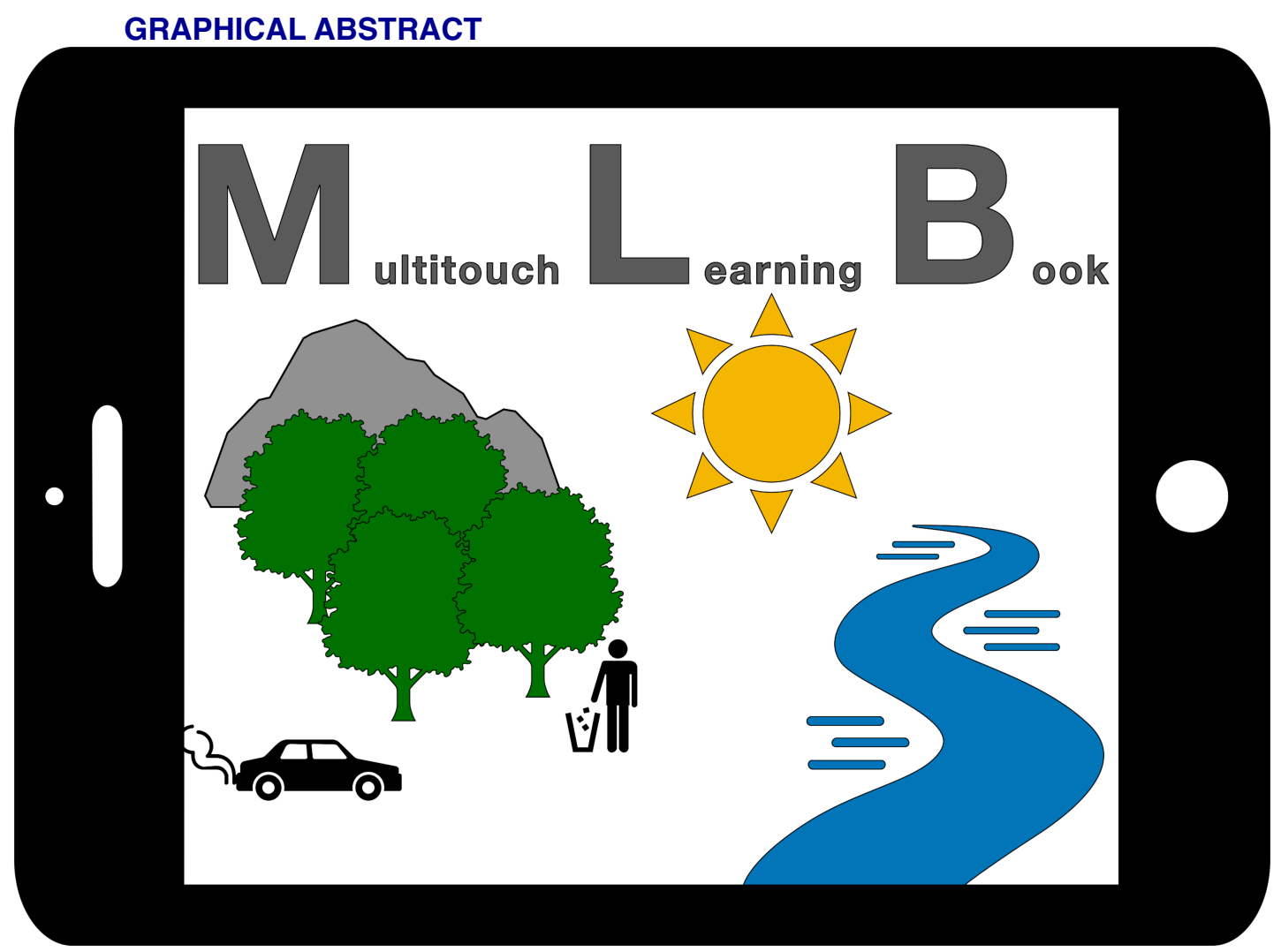

\section{KEYWORDS}

High School/Introductory Chemistry, Interdisciplinary/Multidisciplinary, Curriculum, Hands-On Learning/Manipulatives, Multimedia-Based Learning, Applications of Chemistry, Environmental Chemistry

\section{INTRODUCTION}

Especially in today's world, digital media are irreplaceable, both in the private and school sector. The Conference of Ministers of Education and Cultural Affairs has published the "Competencies in the Digital World". ${ }^{1}$ Digital media must be used in a technically meaningful and didactically reflective manner so that added value in the sense of science education can result.

The multitouch learning books (MLB) we have developed intend to show how exactly this combination of general technical and digital skills can succeed. Interactive e-books are learning companions that are used in the teaching and learning laboratories (Schülerlabors) NanoBioLab (Saarland University) and iChemLab (Weingarten University of Education). MLBs in Schülerlabors promote the method of inquiry-based learning in an exceptional way. There is a differentiated support allowed by interactive widgets that there is a high possibility for individualization. ${ }^{2}$ The combination of multitouch learning books and inquiry-based learning provides an opportunity to promote problemsolving competencies in a way that explores a real-life problem independently with individual decisionmaking using support tools. ${ }^{3}$ In this context chemistry topics can be connected to sustainable development. Protection of phosphate resources as a socio-scientific issue allows pupils to see the individual and social relevance and a professional vantage to chemically analyze industrial solution approaches to solve this problem.4,5 Furthermore, interactive widgets can connect different places of learning in a way that links school topic, laboratories experiments, and industrial processes. MLBs serve as a connection, both between formal and nonformal places of learning and between the transfer of competences for pupils. 6,7 
This relation is precisely where the project starts and provides didactically reflected and competence-oriented teaching-learning scenarios. Teachers act in these scenarios as supervisor to support pupils in case of technical problems and to verify understanding of the learning content and to support a critical reflection of pupils' results. During the usage of the MLB in the course there is no more time needed compared to other pedagogical approaches, if the method is practiced regularly. In the course of the project, multitouch learning books for advanced chemistry lessons with a focus on technical-scientific and socially relevant aspects of chemistry were developed and evaluated. This fact made it possible to provide a digital material pool for chemistry teachers. The dissemination of newly developed multitouch learning books and targeted events for pupils, prospective teachers, and teachers will allow a more extensive reach of the transformation of science education.

\section{IMPROVING THE LEARNING EXPERIENCE: MULTITOUCH LEARNING BOOKS TO PERFORM EXPERIMENTS}

\section{Multitouch Learning Books in a Chemistry Laboratory To Promote Digital Learning}

A multitouch learning books is an interactive learning companion with additional dynamic, interactive, non-linear, and modular materials such as worksheets and individual support are integrated. ${ }^{3}$ Huwer and Eilks define them as a learning companion that includes designed elements in the sense of a learning portfolio. ${ }^{3}$ There are two types of these kinds of learning companions. The first type, modifiable teacher-created MLBs, can be adapted for different learners. With the software iBooks Author, teachers can create and change their books for this purpose. 8 The second type of learning companion of MLBs cannot be adapted by teachers themselves. These are only "ready to use"; however, they have been approved by professionals to align with the curriculum. ${ }^{3,9}$ There are several examples of these Multitouch Learning Books. ${ }^{10-12}$ But regional references or individual class-internal support cannot be taken into account-a central need that mainly affects Schülerlabor. Furthermore, it can take much time to create these e-books; thus, they are often not adapted to current events (e.g., Fridays for Future).

Customizable multitouch learning books are flexible in their presentation to pupils. Regional aspects and aspects of individualization can be integrated at this point. ${ }^{12}$ Thus, it is also possible to integrate the offerings of a Schülerlabor in the school context. Due to this adaptation of the contents, individual learning in the classroom can be promoted. This form of individual teaching makes it possible to provide all the necessary materials to appropriate groups of pupils within one medium (the e-book). Texts, pictures, videos, animations, and dynamic visualizations can be profitably integrated.13-16 Thus, dynamic processes at the particle level can be implemented in the e-book, so that the pupils can obtain a dynamic visualization of processes that cannot be observed. All these potentials lead to the possibility of providing every pupil with their own individualized e-book connected to their learning level. Alternatively, there could be several variants of learning companion from which pupils can choose the book they want in order to work in a self-regulated manner, which results in a higher degree of self-regulation.1,17

All these aspects of individual learning, such as a natural variety of methods as well as flexibility in the presentation of materials, allow for a profitable use of powerful interactive tasks in class. ${ }^{18}$ Profitable in this case means that the pupils can choose the tasks and the individual help in a selfdirected way, depending on their strengths and weaknesses. While the pupils work on the tasks, the help can be called up at the appropriate time. This environment can also lead to integrated, more complex tasks being seen as a challenge, which in turn results in individualized learning. ${ }^{19}$ The help provided in the e-book can be set up in such a way that the pupils receive help only after one-time processing and on request. Besides, there is a media option to present the tasks and aids in different ways. For example, drag-and-drop tasks, self-assessment cloze texts, or only digitally possible task formats can be integrated. Also, it is possible to perform and repeat these tasks as often as possible with built-in self-control. This fact also has the advantage that the teacher gains additional time to address and correct individual problems in the classroom. Multitouch learning books also offer the possibility to follow individual non-linear learning paths. Through a targeted implementation of hyperlink buttons, pupils can search for and follow their solution. 
Fields of Application and Discussion of Advantages of a Multitouch Learning Book

Multitouch learning books play an essential role in science education, including non-formal learning environments, such as Schülerlabors. ${ }^{3}$ This necessary connection between a non-formal and a formal learning environment defines a criterion for the curricular success of a Schülerlabor. Additionally, this laboratory event must not seem like an independent trip, it is even more critical to connect the curricular and extracurricular learning by preparing it in school beforehand, and afterwards. ${ }^{20-22}$ It is often unavoidable that the materials from the Schülerlabor are challenging to combine with the materials from the school preparation and follow-up. A multitouch learning book offers the possibility of presenting these materials uniformly and with a connection. Thus, the visit to the Schülerlabor can be implemented as a submodule in the ongoing lessons. Thus, the materials developed in the Schülerlabor can be worked on and followed up directly in one medium. For example, the documentation of the experiment in the laboratory is saved for follow-up work in the school. The MLBs developed by us for our Schülerlabor are also didactically reflected and are provided to teachers in advance as a modifiable version. ${ }^{13}$

Various added values of the learning companion compared to the analogous experiment variant can be briefly synopsized as follows:

- Individual experiments are connected via links in the multitouch learning book, thus breaking up a linear learning path. This non-linear learning path can promote the self-determination of the pupils when experimenting.

- Integration of interactive applications (widgets) allows a better adaptation of the experimental instructions to the learning process and individual needs of the pupils.

- Integration of animations can significantly increase understanding and problem-solving skills.

- Integration of individual learning tools and experimental tools, such as $\mathrm{pH}$ measurement with digital data acquisition, leads to an important link between the various didactic functions of digital media. The Schülerlabor module enables meaningful networking of non-formal and formal learning environment. In this context the learning companion includes the function as an experimental tool. In this regard it is possible to control the reaction conditions of the experiment all the time without losing the focus of the experiment's handling. At the same time, there is a linkage between the experiment and the real industrial process because the reaction is controlled by digital data measurement.

Phosphate Recovery as a Topic in Informal and Formal Education

There are different methods to integrate sustainable development in chemistry education. Rauch defines three models for Education for Sustainable Development (ESD) in chemistry: (i) adopting green chemistry principles; (ii) selecting sustainability strategies as topic; and (iii) using socio-scientific issues. ${ }^{23}$ These "models can contribute to learning about or for sustainable development". ${ }^{24}$ Socioscientific issues (SSI) focus both learning for as well as learning about sustainable development and promotes system thinking. ${ }^{24}$ The developed learning environment uses the necessity of phosphorous recovery as SSI with multiperspective and interdisciplinary considerations. Phosphorous is a growthlimiting factor and essential for human beings and plants. For this reason, it is an essential component in fertilizers and necessary for agriculture. ${ }^{5}$ Phosphate is vital for the economy, but there is also a high supply risk due to limited resources. Therefore, the EU declares phosphates a critical raw material. ${ }^{25}$ In connection with these problems, environmental technology is developing recovering processes for phosphate from wastewater and sewage sludge. ${ }^{4}$ This should reduce potential risks and the impact on the environment as a result of the closed phosphate cycle by the recovery processes.

This problem of limited phosphate resources and high requirement of the raw material at the same time can be a topic in chemistry. Generally, chemistry curricula are not focused on the element phosphorus or the phosphates, although they have an everyday life relevance. Equally, there is a significant lack in the integration of sustainability-related topics in problem-oriented teaching, despite the central role of chemistry for sustainable development. ${ }^{26}$ Phosphorus recovery can be integrated in chemistry education as a socio-scientific issue with a sustainable focus to empower the relevance of scientific learning. Furthermore, this problem-based context with multi-perspective problem-solving 
aspects indicates chemistry's need for solving challenges in the context of sustainable development and the impact of scientific technologies to reach the United Nations Sustainable Development Goals. ${ }^{4}$ The topic of phosphate recovery is appropriate as a socio-scientific issue due to its authenticity, relevance, the possibility of discussion, and different points of views in society; furthermore, phosphate recovery is a meaningful techno-scientific query. ${ }^{26}$

Due to its multidimensional nature, the topic of phosphorus recovery connects cross-disciplinary aspects. It includes perspectives from different scientific fields, including geography, biology, economy, and chemistry. ${ }^{5}$ The topic also connects formal learning in school with nonformal learning in a Schülerlabor. The basis for a transdisciplinary approach and the connection of formal and nonformal learning is embedded in a digital learning environment that is divided into three parts: preparation; laboratory work; and follow-up. ${ }^{5}$ The preparation explains "the economic, societal, and geographical dimensions of the topic" in a digital presentation (using Prezi). ${ }^{5}$ Afterwards, pupils compare different industrial recovery processes in a laboratory experiment. For linking formal education in school and nonformal education in Schülerlabor, the topic content was integrated into a digital learning environment in the context of a virtual learning company.

\section{The Virtual Learning Company}

Work in this Schülerlabor develops the topic's main component and embeds the experiments in a virtual learning company designed in a digital learning setting. In the first step, pupils perform qualitative and semi-quantitative analysis of phosphate samples to learn the basic working techniques of the recovery processes. After that, pupils perform experiments to recover phosphate from model sewage sludge. In this way, the experiments embedded in the virtual learning company illustrate the relevance of phosphorus recovery. In the introduction, the importance of growth-limiting factor phosphorus is shown to pupils via an e-mail message and a video.

Pupils evaluate qualitative and quantitative analytical procedures for phosphate analysis. They will apply these learned analytical methods in the contextualization by testing the different phosphorus recovery processes (see figure 1). Every process is structured in steps: leaching, filtration, crystallization, and quantification. 5 The experiments vary in the leaching substance and the precipitation agent. The pupils will assess the feasibility and efficiency of these methods according to given evaluation criteria.

In the contextualization, the class is divided into a division of qualitative and quantitative analysis. In groups of three pupils (maximum), they work through all stations of their division. For the procedures in the decontextualization period, one expert from the quantification division works together with an expert from the qualification department. Each team carries out and evaluates only one phosphorus recovery procedure. The experiment instructions and supporting materials are presented in an interactive digital learning environment that enables guided-inquiry learning. ${ }^{5}$ For higher authenticity, the virtual learning company instructions are designed as e-mail messages and learning aids as fictive chats with an expert. In this way, the Schülerlabor and industrial processes of environmental technology are linked to phosphate recycling. 


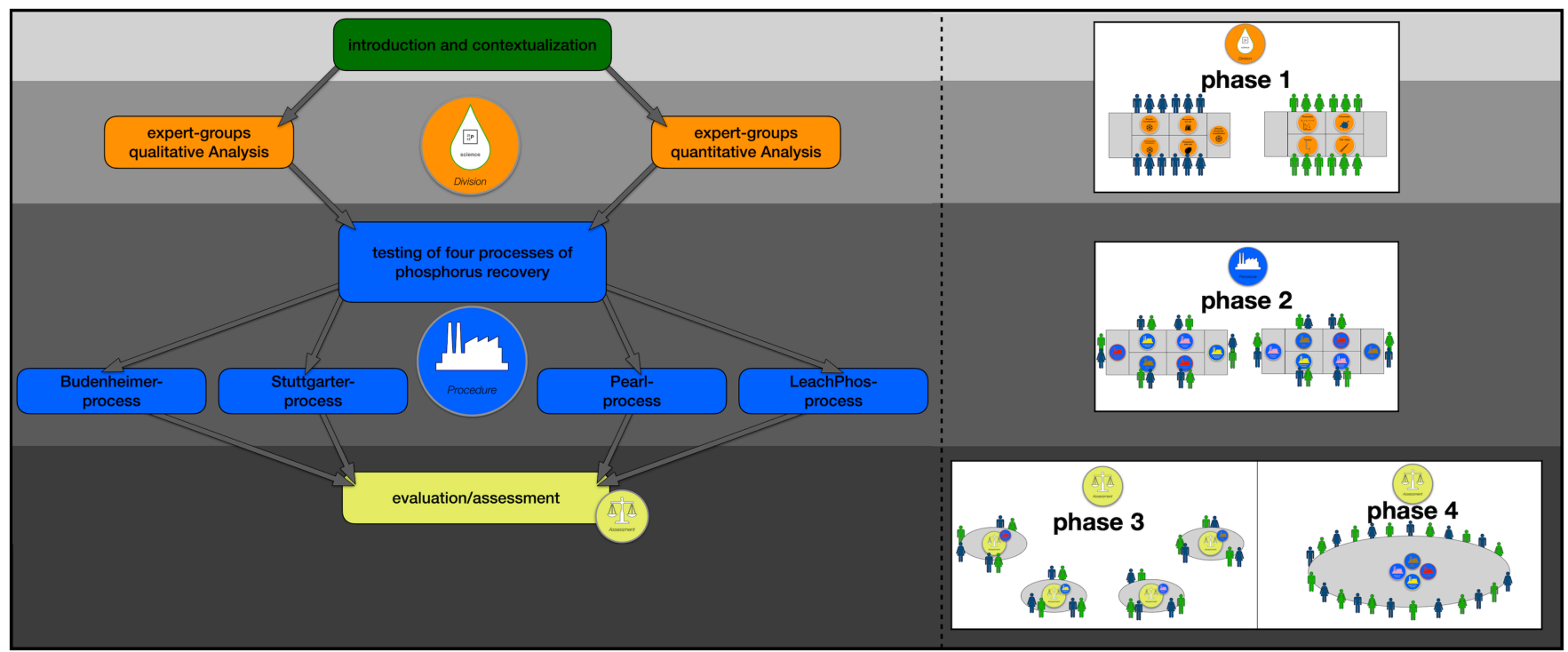

Figure 1. Organization of the learning company in four phases: introduction; divisions; procedures; and assessment.

Because of the composition of the teams and the structure of the digital learning setting, peer-topeer support is possible, as the special procedures contain qualitative and quantitative components. The expert teams of a procedure discuss their results among themselves for evaluation. In phase 4, the evaluation of the individual procedures is presented and discussed in the plenum. This allows the advantages and disadvantages of the individual procedures to be assessed and evaluated among themselves. The following section describes the digital learning tool in detail and shows possibilities for linking formal and non-formal education in an authentic context of sustainable development.

\section{A VIRTUAL LEARNING COMPANY: DIGITAL LEARNING AND EDUCATION FOR SUSTAINABLE DEVELOPMENT IN A MULTITOUCH LEARNING BOOK}

\section{The Multitouch Learning Book: Phosphorus Recovery}

As described above, the pupils work in the form of a virtual learning company. Here the individual departments and areas of the virtual company are integrated into the interactive e-book. The pupils are first divided into different groups, to ensure the authenticity of the learning scenario. A multitouch learning book supports experimentation in the laboratory, for example. In this digital learning companion, the pupils receive their research assignment with the experiment instructions on one page in the form of an e-mail message, help, and work orders, as well as the possibility to communicate collaboratively with the other expert groups. ${ }^{27}$

During the development of the digital learning environment, special attention was paid to individual support of the learners. For this reason, tremendous support in the form of recorded chat sequences was developed. Information in text, picture, video, and audio form is integrated into the chats so that different types of learners are addressed in the sense of individual support. The support refers to linguistic, technical, experimental, and cognitive problems.

The e-book pages shown in Figure 2 present the navigation within the multitouch learning book. After the introduction on the first page, pupils see the overview page. Here they can choose between the individual phases of the virtual learning company. The orange button leads pupils to the department selection where they work on either the qualitative or quantitative analysis. The blue button takes pupils to the overview page of the four different large-scale processes (Budenheimer, Pearl, Stuttgarter, and LeachPhos processes) for phosphorus recovery, where pupils can also select their assigned process. Either from there or also via the menu, pupils can access the evaluation (yellow button) of different processes. 


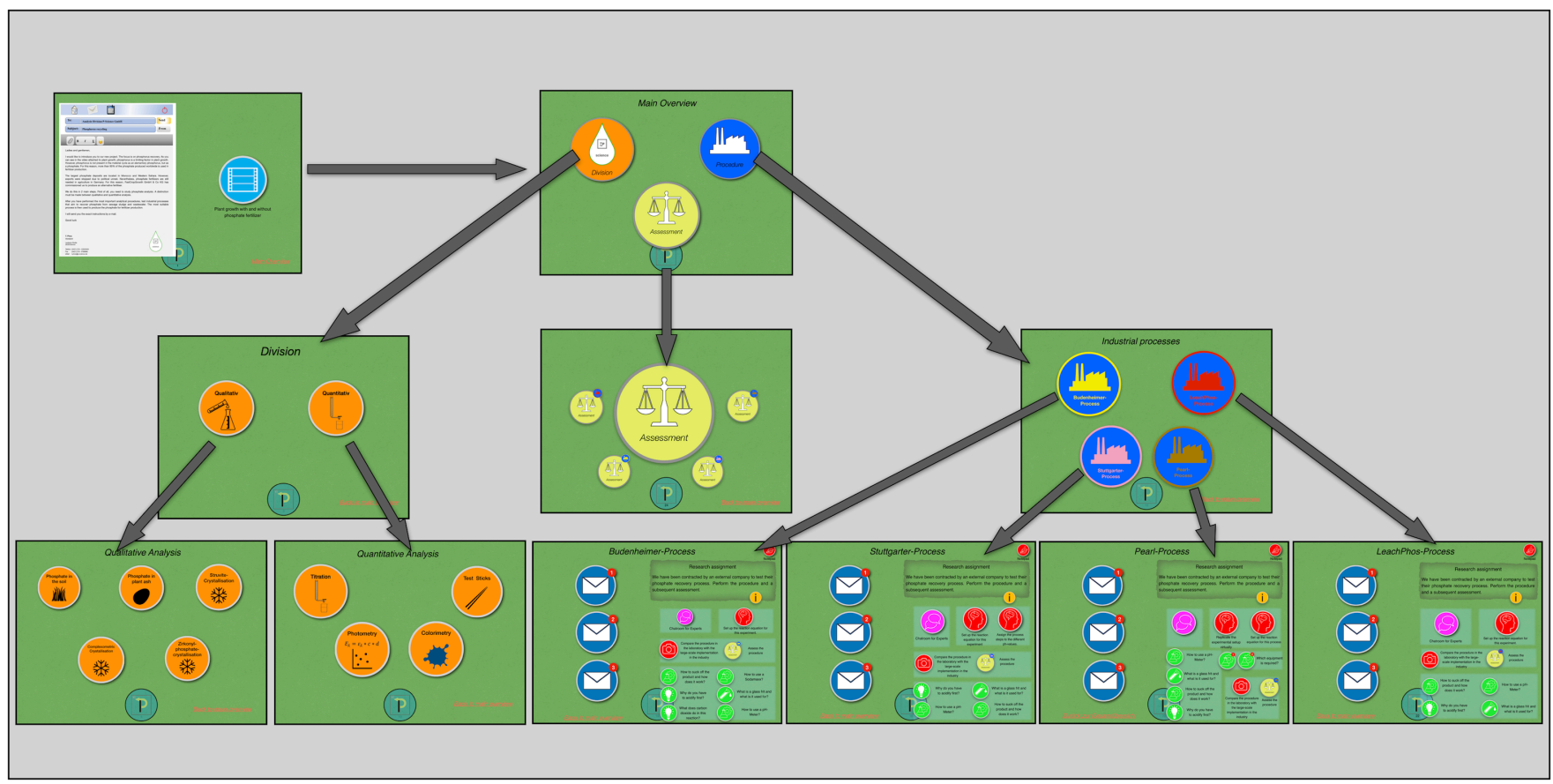

Figure 2. Overview of navigation through the e-book about phosphorus recovery.

Part 1: Introduction. At the beginning of the unit, pupils should be sensitized to the topic “ phosphates in the environment". In a first e-mail message from the management, the urgency and importance of this topic is made clear (see figure 3). In addition, the e-mail message contains a video that illustrates the effect of phosphate fertilizers on plant growth. The whole group should discuss together what the necessity of phosphorus recovery consists of and why the use of phosphate fertilizers is essential. 


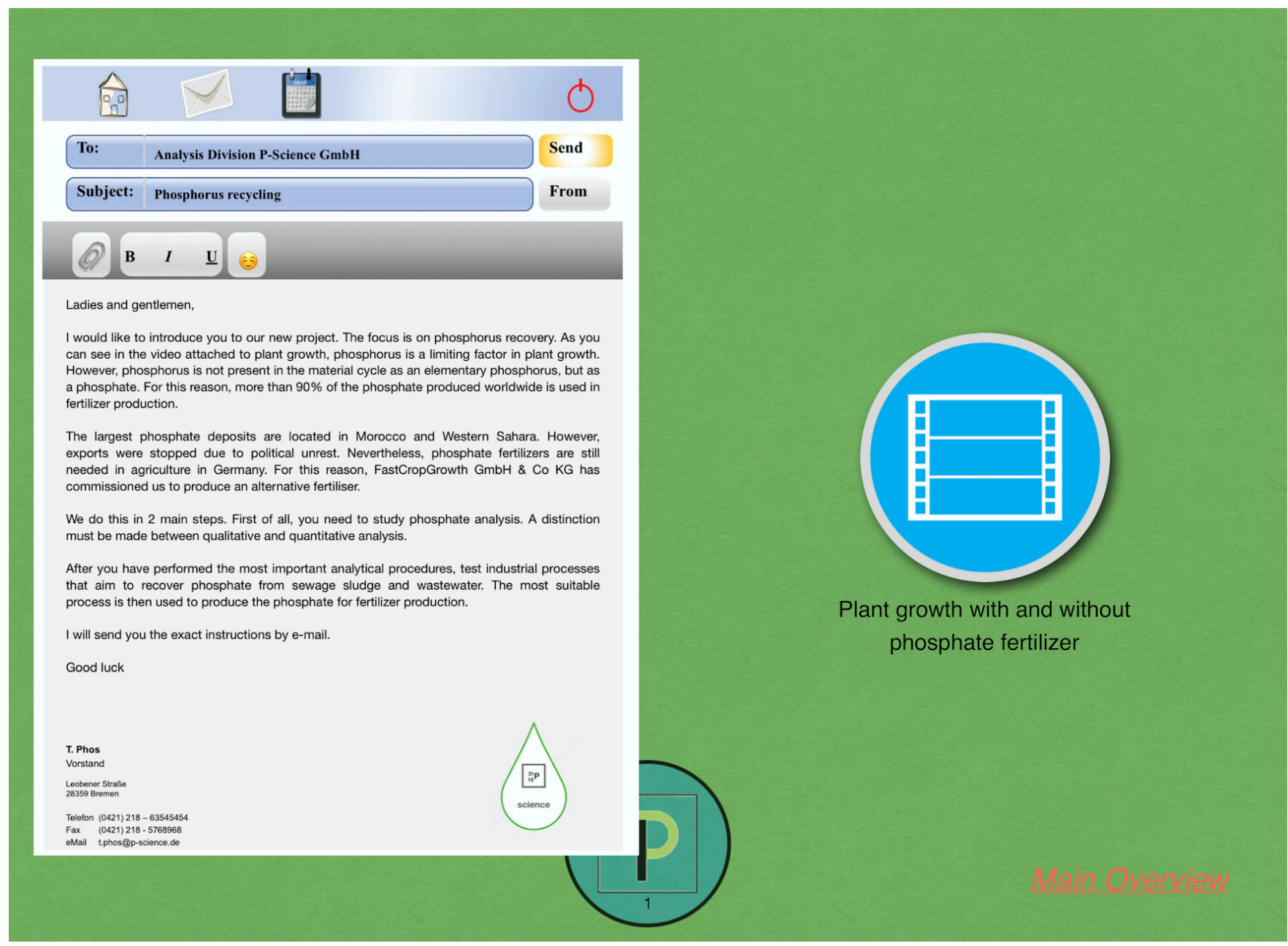

Figure 3. Introduction by an e-mail message of the management of the virtual company.

Part 2.1: Qualitative Division. One-half of the group is assigned to the division for qualitative analysis and detection of various phosphate-containing samples. Each group of three has to get to know all five different methods and perform them experimentally (see Figure 4, finger 1). A separate ebook page is available for each experiment, which is always identically structured. First, pupils receive an e-mail message from the company management (see Figure 4, finger 2) with the instruction to develop a suitable experiment. In the e-mail message, a first work order is already integrated (see Figure 4, finger 3). In the beginning, pupils should put the experiment instructions in the right order. On the right side of the e-book, the research assignment for the respective experiment is written on top. To document the experiments, pupils should take pictures of their experiments (see Figure 4, finger 4), which they will need in the further course of the experiment. If pupils still need additional help around the experiment, they can get further support by clicking the green buttons (see Figure 4, fingers 5 and 6). Throughout the presented multitouch learning book, pupils get help for experiments, language, devices, and understanding through interactive chats with their supervisor. In creating this type of assistance, authentic scenarios should help to virtually represent the situation of a real company. 


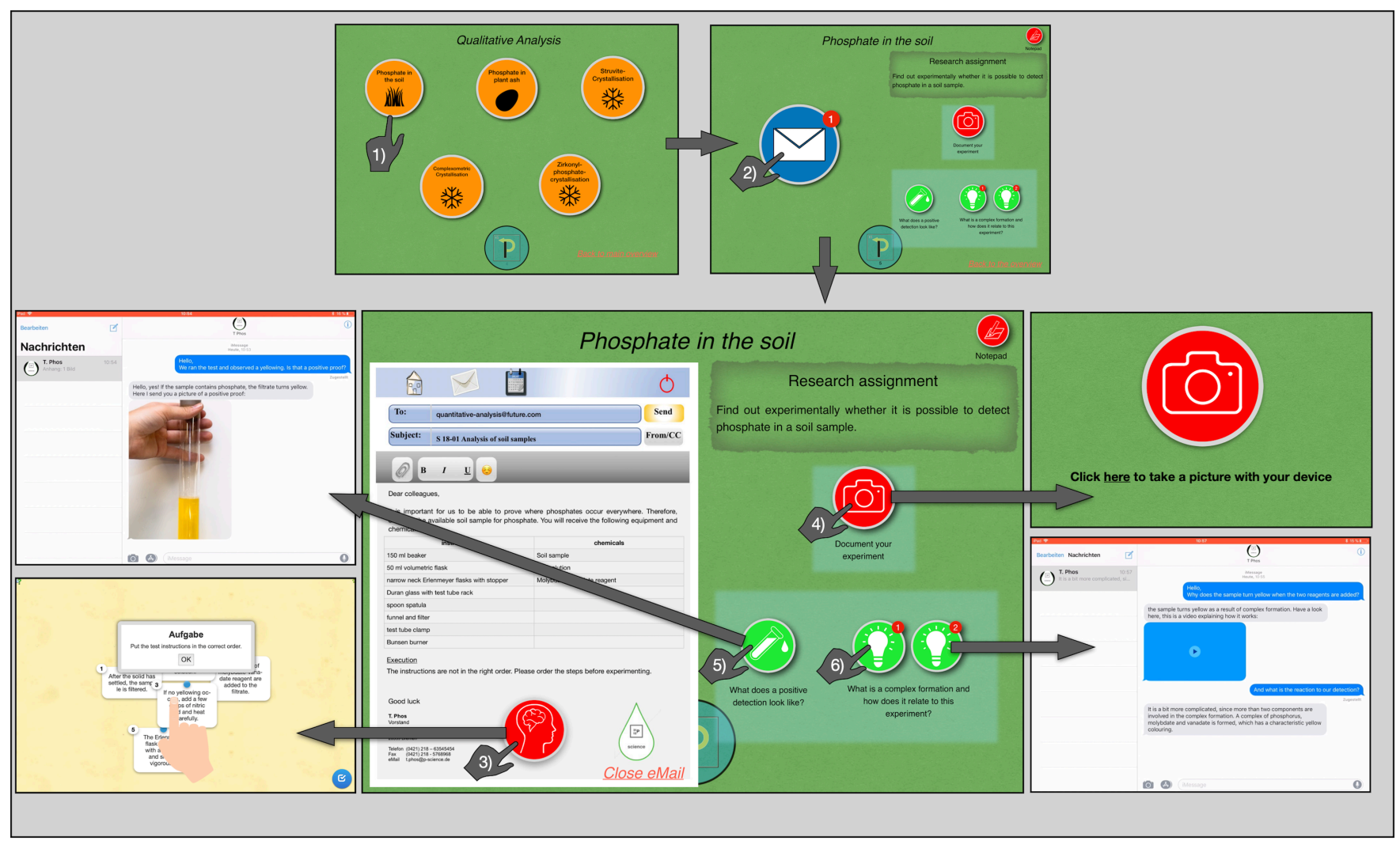

Figure 4. Overview of one qualitative synthesis-phosphate in the soil.

Part 2.2: Quantitative Division. The division of quantitative analysis works on four detection methods for the determination of the content of phosphate-containing substances. Four primary methods were implemented in the multitouch learning book. Besides titration, different test sticks, and photometry, the individual groups of pupils should get to know colorimetry (for navigation, see Figure 5). As in the qualitative department, the experts for qualitative synthesis should experimentally perform and understand all four methods. As described in part 2.1, the e-book pages are also identically structured. For each experiment, pupils get an e-mail message that introduces them to their selected experiment. In contrast to the parallel group of experts, these pupils receive more support in the form of differentiating assistance for these experiments. For each experiment, an identically structured page is included in the e-book. Pupils are given additional tasks to complete in addition to the main research assignment. Figure 5 shows the uniform structure of such a page. For example, self-assessment tasks are implemented as a further cognitive exercise. In this example, pupils are supposed to sort the samples A-D according to ascending concentration and then get direct feedback from the book (see Figure 5, finger 2). The calculated concentrations are to be shared with the other groups using a collaborative tool—an interactive pinboard—so that a more accurate concentration can be determined by all groups together using shared measurement repetition (see Figure 5, finger 9). 


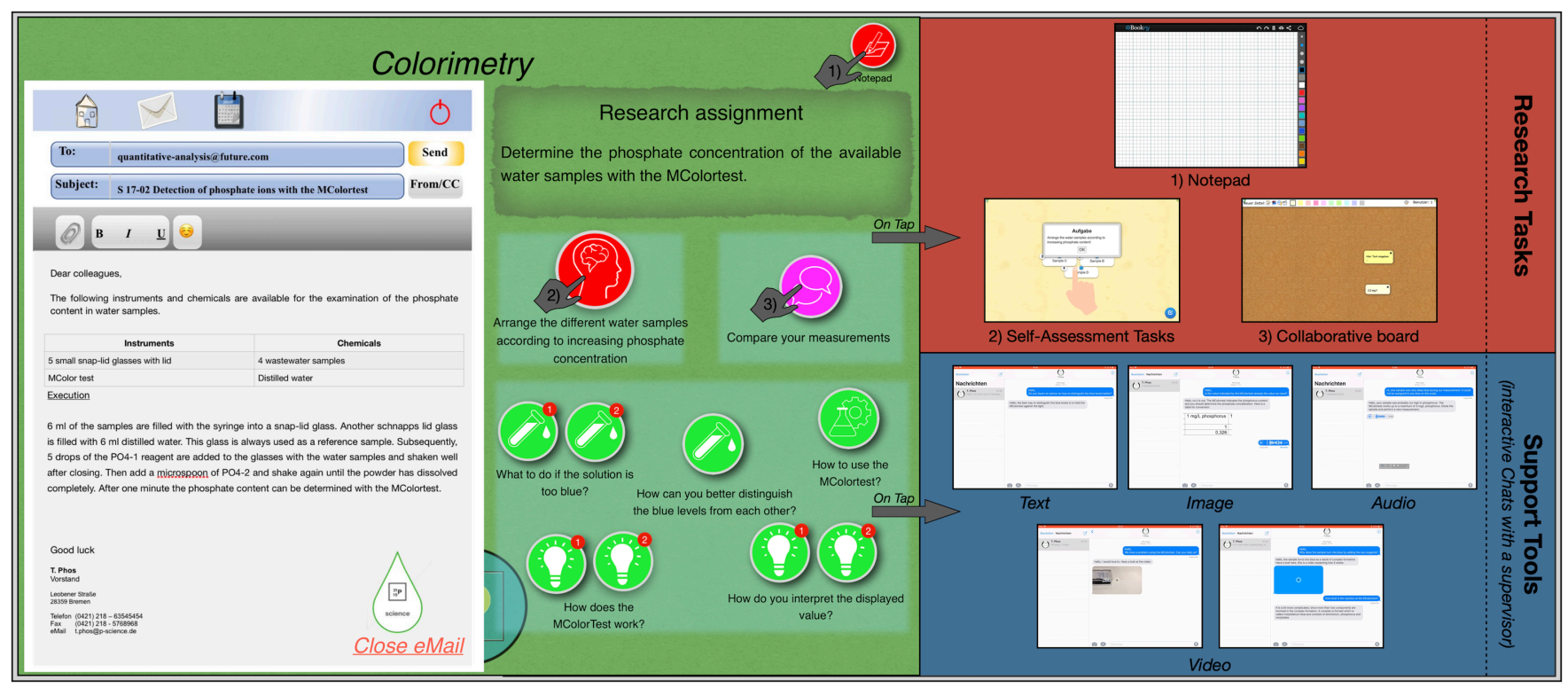

Figure 5. Overview of one quantitative synthesis - colorimetry-with research tasks (red) and support tools (blue).

In order to work on additional tasks, pupils also have an individual notepad in which they can note by hand their intermediate results or even thoughts (see Figure 5, finger 1). For each experiment, as well as later in the procedures, support tools throughout help pupils with the task. All individual support tools also follow a uniform format (see Figure 5, blue area).

Interactive chats with the supervisors provide pupils with experimental support as well as help in understanding the equipment and its general use. These interactive chats are also presented in various forms. Either the supervisor replies with a text only or sends supplementary images, records voice messages, or sends a video for the proper processing of the experiments, or sends explanatory videos for cognitive understanding of the experiment. In this way, pupils are exposed to auditive, visual, and audio-visual channels of processing, which can lead to better processing of the content in working memory. As these experiments are sometimes of high complexity, pupils must be provided with more assistance so that the knowledge they acquire can be applied to other subjects later on.

Part 3: Phosphorus Recovery Process Experiments 1-4. The central component of this entire unit is testing and evaluating various large-scale processes and downscaling these to the laboratory. Since all four processes follow a common scheme, pupils are given additional information on the general flow of such a recovery process (see Figure 6, finger 1). The individual groups of pupils are assigned one process each and carry it out. Experts from each of the previous departments must be in the group because both technical contents are necessary for the development of an experiment. To enable the different groups to work together and share their knowledge from the previous experiments, an interactive chat was implemented in the e-book, which is displayed on all tablets simultaneously (see Figure 6, finger 2). In order to achieve the time-delayed editing of the experiment stations, a direct communication is at this point not meaningful. The chats collect all experimental results to discuss them at the end in a direct presentation.

The chat function links the individual e-books again to each other, enabling collaborative work between the various expert groups. Further additional tasks have been inserted, in which pupils have to present their experimental set-up virtually by drag and drop before they start their experiment, as well as the respective reaction equations for the experiment to be performed (see Figure 6, fingers 3 and 4). Since these procedures are unique and challenging, it is necessary to present enough supporting material that pupils can solve this experimental task as described in part 2 below (see Figure 6, green buttons). An essential part of the evaluation process of the individual procedures is the comparison between the large-scale application with the variant carried out in the laboratory. As shown in Figure 6, photo widgets are inserted to evaluate the individual components of the process to 
record their individual steps in the laboratory with pictures and to place them at the appropriate position in the large-scale process diagram.

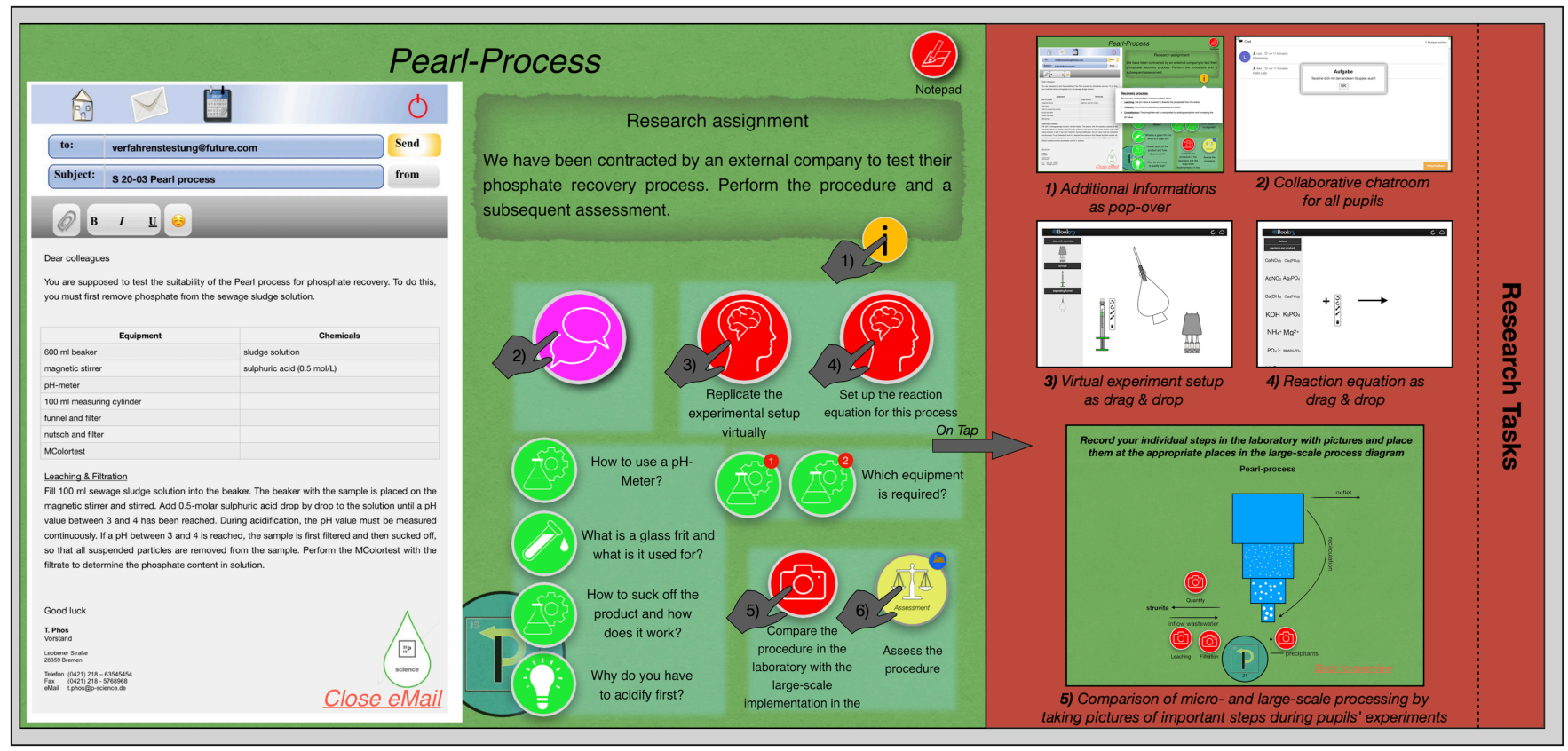

Figure 6. Overview of one phosphorus recovery process, the Pearl process.

Part 4: Evaluation of Phosphorus Recovery Processes. After pupils have completed all experimental and cognitive tasks the effectiveness and sustainability of the proper procedures, the expert groups discuss the different procedures (see Figure 6, finger 6). For this purpose, an interactive blackboard with keywords for evaluation is available to pupils for each process. This compilation will be discussed in a final session in the plenum. Finally, the processes should be compared with each other by all pupils together.

\section{EVALUATION}

Four classes $(n=89$; tenth grade; ages $15-17)$ tested the digital learning companion and were statistically evaluated between December 2019 and February 2020. Pupils first saw the interactive learning companion in school, the formal learning location, before the actual Schülerlabor visit. The introduction to the topic (part 1) was thus carried out by the teacher beforehand. In the nonformal learning environment, pupils could experiment for $3 \mathrm{~h}$. After the pupils had finished the unit, a questionnaire was filled out by them. A summary of the pupils' Likert-scaled answers is provided in Figure 7. 


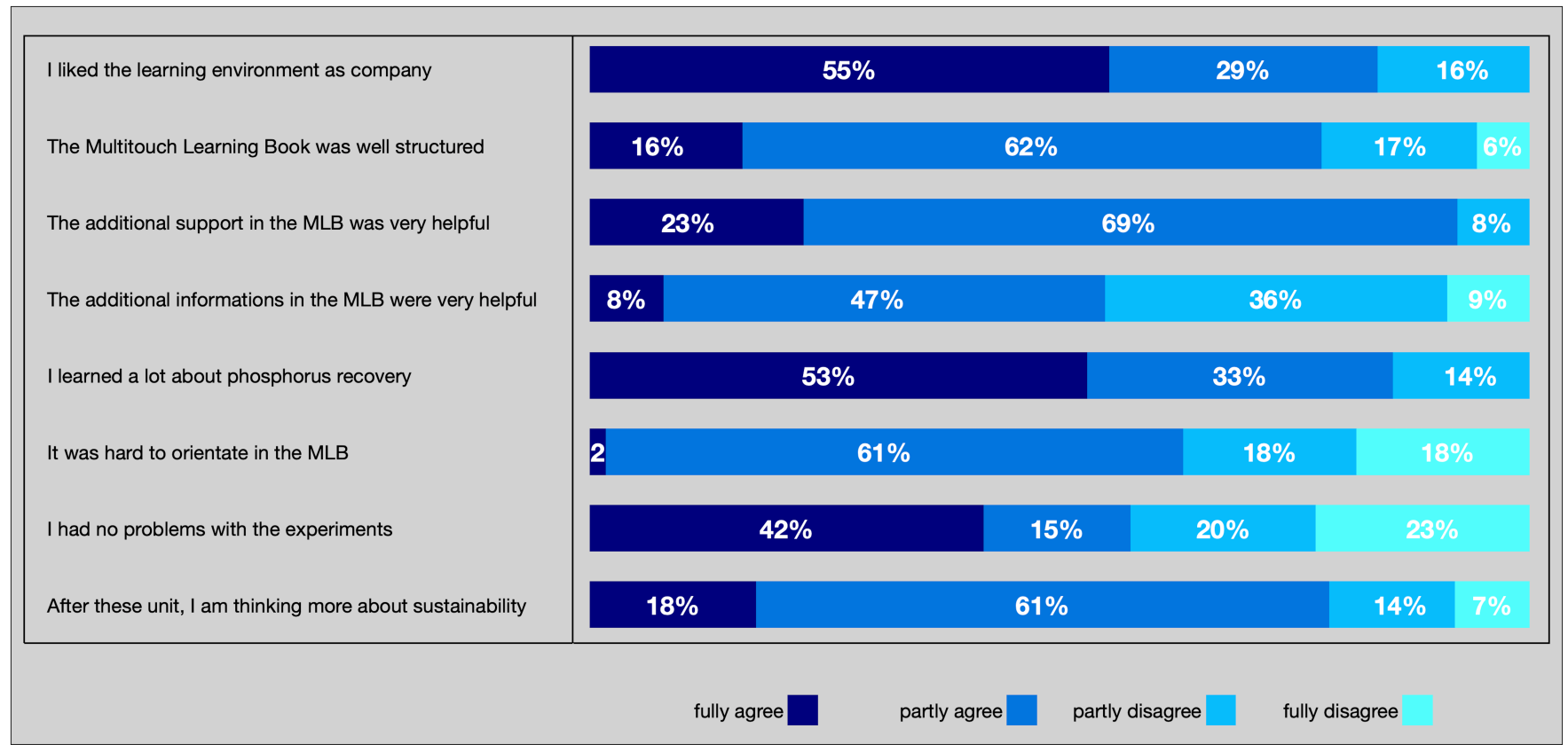

Figure 7. Percentage distribution of selected items from the results of the study on the use of the multitouch learning book on phosphorus recovery $(n=89)$.

The digital learning environment was perceived as very positive by the pupils. In fact, $84 \%$ of respondents said that they either entirely or at least partially perceived the virtual learning company as positive. This fact also means that $86 \%$ of the pupils have learned new content about phosphorus recovery and $79 \%$ will change their awareness of sustainability after the series of lessons. Additionally, it can also be seen that the pupils have lost orientation during the experiments due to the immense processing of information. For example, $47 \%$ said that some of them had difficulties in finding their way around in the digital media. However, more than half of the pupils considered the additional information and support provided by the e-book to be helpful.

The evaluation clearly shows that the pupils were partly overloaded by the amount of material. This is shown by the fact that $62 \%$ of the pupils had difficulties finding their way around the MLB. On the other hand, $78 \%$ of the pupils say that the MLB was well structured, which in turn indicates that the lack of orientation was compensated by the clear structure. It can also be seen that many words within the MLBs email layout made it easy for pupils to lose their orientation. For this reason, the authors plan to rework the e-book with fewer text passages and more visual or auditive input to provide better orientation.

\section{CONCLUSION}

The developed learning scenario of a virtual learning company (in our case phosphate recycling) was very motivating for the participating pupils. Due to a large amount of content, it could be determined that at some point, pupils lost orientation in the e-book and therefore had to ask for help from a "real" supervisor (the teacher). In addition, the support tools in the analog version were used much less, which resulted in increased frequency in the request for the supervisors. Multitouch learning books are well suited to make complex content available to pupils in a structured way compared to analog use of pen and paper. Especially the previously presented materials show that nonlinear guidance promotes individual learning. Further studies will also look at how a more structured presentation of the individual e-book pages can help to promote self-regulated learning and thus also support individual solutions. In addition to the motivational skills of this learning unit, the presented study shows that pupils have generally developed a better awareness of sustainability. By using a context-oriented series, it can therefore lead to the pupils being more aware of their 
environment and transforming this into their everyday life. The digital learning company can also be used to support pupils in their career orientation. Working as experts and evaluating processes also enhances the pupils' experience of autonomy, which can increase the awareness of self-regulated work and learning.

The e-book described here was created with the program iBooks Author, enriched with interactive widgets (especially from Learningapps and Bookry) and can be downloaded in the Supportive Informations. Thus, the resource offers good accessibility to external tools, but this also creates a strong dependency. In addition, the book presented is only accessible via iOS, iPadOS, and macOS devices, which automatically excludes other systems. For this reason, it would be preferable to have a platform-independent program that allows such interactive books to be provided to pupils independently of the equipment, while at the same time ensuring interactivity.

\section{ASSOCIATED CONTENT}

\section{Supporting Information}

The Supporting Information is available on the ACS Publications website at DOI: 10.1021/ acs.jchemed.XXXXXXX. [ACS will fill this in.]

The Multitouch Learning Book (.ibook) is available here: https://www.dropbox.com/s/ n2mos 1ogi6v212o/Phosphor-R\%C3\%BCckgewinnung-english.ibooks?dl=0 (accessed 2020-08-21).

\section{AUTHOR INFORMATION}

Corresponding Author

*E-mail: huwer@ph-weingarten.de

*E-mail: johann.seibert@uni-saarland.de

\section{ACKNOWLEDGMENTS}

The authors thank the Deutsche Bundesstiftung Umwelt (DBU) for financial support (Grant number Az. 33729).

\section{REFERENCES}

1. Standing Conference of the Ministers of Education and Cultural Affairs (KMK). The Standing Conference's " Education in the Digital World" Strategy Summary, 2016. https://www.kmk.org/fileadmin/Dateien/pdf/ PresseUndAktuelles/2017/KMK-Strategie Bildung in der digitalen Welt Zusammenfassung en.pdf (accessed 2020-08-21).

2. Huwer, J.; Brünken, J. Individualisierung mit Tablets im Chemieunterricht (Individualization with Tablet Computers in Chemistry Education). Computer + Unterricht. 2018, 110 (30), 7-10.

3. Huwer, J.; Eilks, I. Multitouch Learning Books für schulische und außerschulische Bildung (Multitouch Learning Books for Formal and Non-formal Learning). In Lernprozesse mit digitalen Werkzeugen unterstützen. Perspektiven aus der Didaktik naturwissenschaftlicher Fächer, Schanze, S., Groß, J., Eds.; Joachim Herz Stiftung: Hamburg, Germany, 2017; pp 81-94.

4. Zowada, C.; Siol, A.; Gulacar, O.; Eilks, I. Phosphate Recovery as a Topic for Practical and Interdisciplinary Chemistry Learning. J. Chem. Educ. 2019, 96 (12), 2252-2258.

5. Zowada, C.; Gulacar, O.; Siol, A.; Eilks, I. Phosphorus-A "Political" Element for Transdisciplinary Chemistry Education. Chemistry Teacher International 2019; DOI: 10.1515/cti-2018-0020.

6. Kieserling, M.; Melle, I. Digitisation in Chemistry Lessons-An Experimental Digital Learning Environment with Universal Accessibility. Chemistry Teacher International 2019, 2569-3263; DOI: https://doi.org/ 10.1515/cti-2018-0024.

7. Greitemann, L.; Melle, I. Transferring and Optimizing a Laptop-based Learning Environment for the Use on iPads. World Journal of Chemical Education 2020, 8 (1), 40-46; DOI: 10.12691/WJCE-8-1-5.

8. Peraza-Garzón, J. F.; Estrada-Lizárraga, R.; Zaldivar-Colado, A.; Mendoza-Zatarain, R.; del Carmen Olivarría-González, M.; Zaragoza González, J. N.; Cobián-Campos, J. A. Implementation of "iBooks Author" on the Development of Learning Objects on Blended Learning Education. INTED2O13 Proceedings 2013, 6320-6325.

9. Zeller, D.; Bohrmann-Linde, C.; Kläger, S. Digital Learning Tools for Teaching "Alternative Solar Cells with Titanium Dioxide" (ALSO-TiO 2 ) - A Contribution to Sustainable Development Education. World Journal of Chemical Education 2019, 8 (1), 29-39; DOI: 10.12691/wjce-8-1-4. 
10. Bohrmann-Linde, C.; Kleefeld, S. Can You See the Heat?-Using a Thermal Imaging Camera in the Chemistry Classroom. World Journal of Chemical Education 2019, 7 (2), 179-184; DOI: 10.12691/ wjce-7-2-18.

11. Franco, J.; Provencher, B. Using a Multitouch Book to Enhance the Pupil Experience in Organic Chemistry. J. Chem. Educ. 2019, 96 (3), 586-592; DOI: 10.1021/acs.jchemed.8b00703.

12. Huwer, J.; Bock, A.; Seibert, J. The School Book 4.0: The Multitouch Learning Book as a Learning Companion. Am. J. Educ. Res. 2018, 6 (6), 763-772; DOI: 10.12691/education-6-6-27.

13. Seibert, J.; Kay, C. W. M.; Huwer, J. EXPlainistry: Creating Documentation, Explanations, and Animated Visualizations of Chemistry Experiments Supported by Information and Communication Technology To Help School Pupils Understand Molecular-Level Interactions. J. Chem. Educ. 2019, 96 (6), 2503-2509; DOI: 10.1021/acs.jchemed.8b00819.

14. Seibert, J.; Luxenburger-Becker, H.; Marquardt, M.; Lang, V.; Perels, F.; Huwer, J.; Kay, C.W.M. Multitouch Experiment Instruction for Better Outcome in Chemistry Education. World Journal of Chemical Education. 2020. 8 (1), 1-8; DOI: $10.12691 /$ wjce-8-1-1.

15. Seibert, J.; Marquardt, M.; Pinkle, S.; Carbon, A.; Lang, V.; Perels, F.; Huwer, J.; Kay, C. W. M. Linking Learning Tools, Learning Companion and Experimental Tools in a Multitouch Learning Book. World Journal of Chemical Education 2020, 8 (1), 9-20; DOI: 10.12691/wjce-8-1-2.

16. Seibert, J.; Marquardt, M.; Gebhard, M.; Kay, C. W. M.; Huwer, J. Augmented Reality zur Visualisierung der Teilchenebene am Beispiel des Li-Ion Akkus (Augmented Reality for Visualization at Particle Level in a Li Ion Accumulator). Naturwissenschaften im Unterricht. 2020. 177/178, 86-89.

17. Huwer, J.; Seibert, J.; Brünken, R. Multitouch Learning Books als Versuchsanleitungen beim Forschenden Experimentieren am Beispiel von Süßungsmitteln (Multitouch Learning Books as Experiment Instructions for Inquiry-based Learning about Sweeteners). Der mathematische und naturwissenschaftliche Unterricht. 2018, 3, 181-186.

18. Probst, C.; Seibert, J.; Huwer, J. Naturwissenschaftsdidaktik und Inklusion-To-Do Apps und Multitouch Experiment Instructions als Instrumente zur Förderung der Selbstregulation (Didactical Science and Inclusion-To-Do Apps and Multitouch Experiment Instructions as an Instrument to Promote SelfRegulated Learning). Computer + Unterricht 2020, 117, 14-18.

19. Markic, S.; Abels, S. Science Education towards Inclusion; Nova Publishing: New York, 2016.

20. Garner, N.; Hayes, S. M.; Eilks, I. Linking Formal and Non-formal Learning in Science Education-A Reflection from Two Cases in Ireland and Germany. Journal of Education 2014, 2 (2), $10-31$.

21. Markic, S.; Eilks, I.; di Fuccia, D.; Ralle, B. Heterogeneity and Cultural Diversity in Science Education and Science Education Research; Shaker: Aachen, 2012; p 239.

22. Markic, S.; Wichmann, J.; Affeldt, F.; Siol, A.; Eilks, I. Promoting Education for Sustainability for All Learners by Non-formal Chemistry Laboratories. Daruna 2017, 44, 44-53.

23. Rauch, F. Education for Sustainable Development and Chemistry Education. In Worldwide Trends in Green Chemistry, Zuin, V., Mammino, L., Eds.; The Royal Society of Chemistry, 2015; pp 16-26; DOI: 10.1039/9781782621942.

24. Burmeister, M.; Rauch, F.; Eilks, I. Education for Sustainable Development (ESD) and Chemistry Education. Chem. Educ. Res. Pract. 2012, 13, 59-68.

25. European Commission. Mitteilung der Kommission an das europäische Parlament, den Rat, den europäischen Wirtschafts- und Sozialausschuss und den Ausschuss der Regionen über die Liste kritischer Rohstoffe für die EU, 2017. (Communication from the Commission to the European Parliament, the Council, the European Economic and Social Committee and the Committee of the Regions on the 2017 list of Critical Raw Materials for the EU.) https://ec.europa.eu/transparency/regdoc/rep/1/2017/EN/ COM-2017-490-F1-EN-MAIN-PART-1.PDF (accessed 2020-08-21).

26. Gulacar, O.; Zowada, C.; Eilks, I. Bringing Chemistry Learning Back to Life and Society. In Building Bridges across Disciplines for Transformative Education and a Sustainable Future, Eilks, I., Markic, S., Ralle, B., Eds.; Shaker: Aachen, 2018; pp 49-60.

27. Johnson, D. W.; Johnson, R. T. Cooperative Learning in 21st Century. Anales de Psicología 2014, 30 (3), 841-851. 